\title{
Recovery from daily-life stressors in early and chronic psychosis
}

\author{
Citation for published version (APA):
}

Vaessen, T., Viechtbauer, W., van der Steen, Y., Gayer-Anderson, C., Kempton, M. J., Valmaggia, L., McGuire, P., Murray, R., Garety, P., Wykes, T., Morgan, C., Lataster, T., Lataster, J., Collip, D., Hernaus, D., Kasanova, Z., Delespaul, P., Oorschot, M., Claes, S., ... Myin-Germeys, I. (2019). Recovery from daily-life stressors in early and chronic psychosis. Schizophrenia Research, 213, 32-39.

https://doi.org/10.1016/j.schres.2019.03.011

Document status and date:

Published: 01/11/2019

DOI:

10.1016/j.schres.2019.03.011

Document Version:

Publisher's PDF, also known as Version of record

\section{Document license:}

Taverne

\section{Please check the document version of this publication:}

- A submitted manuscript is the version of the article upon submission and before peer-review. There can be important differences between the submitted version and the official published version of record.

People interested in the research are advised to contact the author for the final version of the publication, or visit the DOI to the publisher's website.

- The final author version and the galley proof are versions of the publication after peer review.

- The final published version features the final layout of the paper including the volume, issue and page numbers.

Link to publication

\footnotetext{
General rights rights.

- You may freely distribute the URL identifying the publication in the public portal. please follow below link for the End User Agreement:

www.umlib.nl/taverne-license

Take down policy

If you believe that this document breaches copyright please contact us at:

repository@maastrichtuniversity.nl

providing details and we will investigate your claim.
}

Copyright and moral rights for the publications made accessible in the public portal are retained by the authors and/or other copyright owners and it is a condition of accessing publications that users recognise and abide by the legal requirements associated with these

- Users may download and print one copy of any publication from the public portal for the purpose of private study or research.

- You may not further distribute the material or use it for any profit-making activity or commercial gain

If the publication is distributed under the terms of Article $25 \mathrm{fa}$ of the Dutch Copyright Act, indicated by the "Taverne" license above, 


\title{
Recovery from daily-life stressors in early and chronic psychosis
}

\author{
Thomas Vaessen a, b, *, Wolfgang Viechtbauer $^{\text {c, a }}$, Yori van der Steen ${ }^{\text {d, c }}$, \\ Charlotte Gayer-Anderson ${ }^{\mathrm{e}}$, Matthew J. Kempton ${ }^{\mathrm{f}}$, Lucia Valmaggia ${ }^{\mathrm{g}}$, h, \\ Philip McGuire f, h, Robin Murray f, h, Philippa Garety ${ }^{\mathrm{g}, \mathrm{h}}$, Til Wykes ${ }^{\mathrm{f}, \mathrm{h}}$, Craig Morgan e, h, \\ Tineke Lataster ${ }^{c}$, Johan Lataster ${ }^{\text {i, c }}$, Dina Collip ${ }^{\text { }, ~ D e n n i s ~ H e r n a u s ~}{ }^{\text {c, }}$ Zuzana Kasanova a, \\ Philippe Delespaul ${ }^{\mathrm{c}}$, Margreet Oorschot ${ }^{\mathrm{c}}$, Stephan Claes ${ }^{\mathrm{b}}$, Ulrich Reininghaus ${ }^{\mathrm{j}, \mathrm{e}}$, \\ Inez Myin-Germeys ${ }^{a}$
}

\footnotetext{
a Department of Neurosciences, Center for Contextual Psychiatry, KU Leuven, Leuven, Belgium

${ }^{\mathrm{b}}$ Department of Neurosciences, Mind-Body Research Group, KU Leuven, Leuven, Belgium

${ }^{c}$ Department of Psychiatry and Neuropsychology, School for Mental Health and Neuroscience, Maastricht University, Maastricht, the Netherlands

${ }^{\mathrm{d}}$ GGzE, Institute for Mental Health Care Eindhoven and De Kempen, Eindhoven, the Netherlands

e Centre for Epidemiology and Public Health, Health Service and Population Research Department, Institute of Psychiatry, Psychology \& Neuroscience, King's College, London, UK

${ }^{\mathrm{f}}$ Department of Psychosis Studies, Institute of Psychiatry, Psychology \& Neuroscience, King's College, London, UK

${ }^{\mathrm{g}}$ Department of Psychology, Institute of Psychiatry, Psychology \& Neuroscience, King's College, London, UK

${ }^{\mathrm{h}}$ National Institute for Health Research (NIHR) Mental Health Biomedical Research Centre (BRC) at South London and Maudsley NHS Foundation Trust and

King's College, London, UK

${ }^{\mathrm{i}}$ Faculty of Psychology and Educational Sciences, Open University, Heerlen, the Netherlands

${ }^{j}$ Department of Public Mental Health, Central Institute of Mental Health, Medical Faculty Mannheim, University of Heidelberg, Germany
}

\section{A R T I C L E I N F O}

\section{Article history:}

Received 5 November 2018

Received in revised form 10 March 2019

Accepted 13 March 2019

Available online 28 March 2019

\section{Keywords:}

Recovery

Stress

At-risk mental state

First-episode psychosis

Schizophrenia

Ecological momentary assessment

\begin{abstract}
A B S T R A C T
Initial affective and psychotic reactivity to daily stressors is altered in psychosis, and most notably in early psychosis. In addition to altered initial stress reactivity, results from studies using Experience Sampling Methodology (ESM) and psychophysiological measures indicate that impaired recovery from mild stressors may also be a risk factor for mental illness.

The current ESM study investigated affective recovery from daily stressors in chronic psychosis patients $(C P ; n=162$ ), individuals at early stages of psychosis (EP; $n=127)$, and healthy volunteers $(H V ; n=220$ ) assessing fluctuations in negative affect (NA), tension, and suspiciousness ten times a day on six consecutive days. Recovery was operationalized for all three variables as the return to baseline (i.e., level at $t_{-1}$ ) following the first stressful event of a day (i.e., $t_{0}$ ).

The EP group showed a delayed recovery of NA $\left(t_{1}-t_{3}: B=0.185 ; p=.007\right.$ and $\left.B=0.228 ; p=.002\right)$ and suspiciousness $\left(\mathrm{t}_{1}: \mathrm{B}=0.223 ; \mathrm{p}=.010\right.$ and $\mathrm{B}=0.291 ; \mathrm{p}=.002$ ) compared to $\mathrm{HV}$ and $\mathrm{CP}$, respectively. Delayed recovery was detected for tension as well $\left(t_{1}-t_{2}: E P>H V: B=0.242 ; p=.040\right.$ and $E P>C P$ : $\mathrm{B}=0.284 ; \mathrm{p}=.023$ ), but contrary to both other momentary states, this effect disappeared when controlling for subsequent stressful events. There were no significant differences in recovery between $\mathrm{HV}$ and $\mathrm{CP}$.

These results suggest that in EP, stressful daily events have longer-lasting effects on overall negative affect and subclinical psychotic-like experiences. Future studies should incorporate physiological and endocrine measures in order to integrate recovery patterns of the different stress systems.
\end{abstract}

(c) 2019 Elsevier B.V. All rights reserved.

\section{Introduction}

Stress sensitivity has been proposed as an important mechanism in the development of psychosis (Collip et al., 2008; MyinGermeys and van Os, 2007; van Winkel et al., 2008). However,

\footnotetext{
* Corresponding author at: Kapucijnenvoer 33, PO box 7001, 3000 Leuven, Belgium.

E-mail address: thomas.vaessen@kuleuven.be (T. Vaessen).
}

how stress impacts mental health remains unclear. It is thought that repeated or chronic exposure to stressors may result in a progressively greater response to future stressors, a concept referred to as sensitization, thereby putting an individual at risk for psychosis (Collip et al., 2008). In line with this theory, Experience Sampling Methodology (ESM) studies investigating reactivity to minor daily hassles have shown that patients diagnosed with a psychotic disorder show an increased affective response to these stressors when compared to individuals without psychosis 
(Myin-Germeys et al., 2001). Moreover, a recent network analysis showed that daily stressors precede psychotic-like experiences in chronic patients, revealing the putative link between stress and psychotic illness (Klippel et al., 2018). Several ESM studies indicated that stress sensitivity is increased in those at risk for psychosis and those in the early stages of psychotic illness (Palmier-Claus et al., 2012; Reininghaus et al., 2016; van der Steen et al., 2017), further implicating stress is in the development of psychosis. These individuals, at risk for or at early stages in the course of psychosis, even show increased stress sensitivity compared to chronic psychosis patients (Palmier-Claus et al., 2012; Reininghaus et al., 2016; van der Steen et al., 2017). This is in line with the stress sensitization hypothesis, posing that exposure to environmental stressors may facilitate the onset of psychosis (Collip et al., 2008). Higher overall negative affect ratings consistently reported in individuals across the psychosis continuum are likely to reflect presence of chronic stressors that individuals experience. The early stages of mental illness often comprise a very stressful period, where stress and the emergence of psychiatric symptoms reinforce each other. In these stages, the association between psychotic symptoms and momentary distress is much stronger than in later stages of psychotic illness (van der Steen et al., 2017). Therefore, a closer examination of the role of stressful daily experiences in early psychosis may provide insight in how these experiences relate to development of psychosis.

Although there is much research on initial reactivity to stress, no study to date has investigated recovery from daily stressors in psychosis. Here, recovery refers to the process in which a system returns to some baseline level following an acute response, thereby reinstating homeostasis. From a psychophysiological perspective, there is evidence of altered baseline autonomous nervous system (ANS) activity in psychosis (Clamor et al., 2016), which may influence the ability to recover from stress. While initial cardiovascular reactivity to stressors may be unaltered across the psychosis continuum (Brenner et al., 2009; Jansen et al., 2000; Lincoln et al., 2015; van Venrooij et al., 2012), there is some evidence suggesting a delayed recovery in terms of heart rate in frank psychosis (Andersen et al., 2018) and those at elevated risk for psychosis (Weintraub et al., 2019). Moreover, decreased responsiveness of the parasympathetic nervous system may result in impaired recovery from stress in psychosis patients (Castro et al., 2008; Montaquila et al., 2015); a similar effect was found in individuals at familial risk for psychosis (Castro et al., 2009). However, no study to date directly compared recovery between individuals at early stages of psychosis and those with chronic psychosis. Cortisol release in response to stress - an important hormone for stress and recovery - appears altered in psychosis as well (Borges et al., 2013; Pruessner et al., 2017; Zorn et al., 2017), and this effect has also been observed in response to daily hassles in an ESM study (Vaessen et al., 2018). Excessive baseline cortisol release, for instance due to chronic stress, may affect brain dopamine function (Walker et al., 2008), which is perturbed in psychosis and plays a major role in the development of psychotic symptoms. Disrupted dopaminergic function in psychosis (Schifani et al., 2018) may in turn result in a decreased cortisol response to stress. According to the coherence/ compensation model (Andrews et al., 2013), the increase in peripheral cortisol following acute stress serves to return physiological and affective responses to baseline. A decreased cortisol response due to chronically increased baseline levels, then, would result in impaired recovery of the other systems. In sum, these findings provide an account of impaired biological stress recovery in psychosis. No study to date, however, has investigated the process of affective recovery from stressors in psychosis.

ESM is an exceptionally well-suited technique to map the temporal course of stress recovery, providing a series of snapshots throughout the day in a naturalistic setting. Recovery, then, can be measured in time following the occurrence of a stressor. Using ESM, recovery analyses have been done in the context of positive affect fluctuations in response to physical activity (Wichers et al., 2012) and reward (Heininga et al., 2019). Yet, no studies to date have identified the pattern of affective recovery in individuals across the psychosis continuum, outlining how they cope with stressful daily situations.

The current study aimed to investigate affective recovery in healthy volunteers (HV) and individuals with psychosis, in response to naturally occurring stressors in everyday life. Furthermore, considering the differences between those at risk for or with first-episode psychosis and chronic psychosis patients (CP) in affective stress reactivity, we aimed to investigate if these differences are apparent in the recovery process as well. From a symptom- or stress-related perspective, the distinction between a clinical highrisk state for psychosis and the diagnosis of first-episode psychosis (FEP) is ultimately arbitrary. As stress may play a different role in the early stages of psychosis compared to chronic psychosis, we aimed to investigate a sample that consisted of both individuals at clinical high-risk for psychosis and FEP patients; a group that will henceforth be referred to as those at early stages of psychosis (EP). We were particularly interested in the temporal course of affect and psychotic-like experiences following a stressful daily event, and tested whether there were group differences in the time course of recovery. More specific, we hypothesized that i) EP and CP would have increased baseline levels of NA, tension, and symptoms compared to HV; ii) EP and CP would show increased initial reactivity to the first stressor of the day on all variables compared to $\mathrm{HV}$, while EP would show increased reactivity compared to CP; and iii) based on findings of impaired physiological recovery, EP and $\mathrm{CP}$ would show impaired affective and symptomatic recovery from this stressful event compared to HV, as reflected in a longer time period before baseline levels are reached.

\section{Materials and methods}

\subsection{Participants}

We used previously collected data from six ESM studies in samples along the psychosis continuum (NARSAD, MAPS, EUGEI, STRIP1, STRIP2, iTHINK; Lataster et al., 2013; Myin-Germeys et al., 2001; Reininghaus et al., 2016; Vaessen et al., 2018; Hermans et al., submitted). Together, these studies provided a dataset of 590 participants, 257 of which were healthy volunteers HV, 141 of which were categorized as EP, and 192 of which were CP. The EP status was determined using either the Comprehensive Assessment of At-Risk Mental State (Yung et al., 1998; Yung et al., 2005) or the Schizophrenia Prediction Instrument, Adult version (SchultzeLutter et al., 2007). For CP, diagnoses were based on either OPCRIT criteria (McGuffin et al., 1991), Community Assessment of Symptoms and History (Andreasen et al., 1992), or Research Diagnostic Criteria (Taylor et al., 1975). All studies were carried out in accord with the guidelines of the local ethical committee. All participants provided informed consent.

\subsection{Procedure}

\subsubsection{Experience sampling}

ESM is a structured diary technique that requires participants to fill out a short questionnaire on their momentary mood, context, and behavior, several times during a day. Three of the studies included used paper and pencil diaries for data collection (MACS, NARSAD, STRIP-1); the other three studies used a dedicated electronic device (STRIP-2, iThink, EUGEI). In all studies, participants were prompted to complete the questionnaire at ten semi-random moments per day between 7:30 AM and 10:30 PM, for six consecutive days. Each day was divided in ten 90-minute blocks, and 
beeps were programmed at a random time point in each block, with at least 15 min between two beeps.

\subsection{Measures}

\subsubsection{Negative affect, tension, and subclinical symptomatology}

Negative affect $(N A)$ was operationalized as the mean score of the items "I feel down", "I feel lonely", and "I feel anxious", which were all measured on 7-point Likert scales. Feeling tense was measured using the item "I feel relaxed", measured on a 7-point Likert scale, which was then reverse-coded such that higher scores indicated feeling less relaxed. The experience of subclinical psychotic experiences was measured with the item "I feel suspicious", which was measured on a 7-point Likert scale.

\subsubsection{Stressful event}

At each measurement occasion ("beep"), participants were asked to think about the most important event that occurred since the previous beep and then rate this event on a 7-point bipolar scale ranging from -3 (very unpleasant) to 3 (very pleasant). A negative rating for this variable was considered a proxy for the occurrence of a stressful event. Let $t_{0}$ denote the beep within a day when the first stressful event occurred, $t_{-1}$ the beep before the occurrence of this event (the 'baseline'), and $t_{1}, t_{2}$, and so on the beeps following this event (the potential 'recovery period'). Days where no stressful event occurred or where the first stressful event occurred on the very first beep of the day were removed (in the latter case, there is no baseline beep). We focused specifically on the first stressful event of the day, since we hypothesized that stressful events may have lingering effects on the variables of interest throughout a day. This way, we were able to use the observation from the beep before the occurrence of this event as a baseline that was not affected by lingering effects of a possible previous stressful event on the same day. Next, we created the variable time_since that indicated the temporal distance of each beep to the occurrence of the stressful event (i.e., $t_{-1}=-1, t_{0}=0, t_{1}=+1$, and so on). Thus, as there were ten beeps per day, time_since ranged from -1 to +8 with 0 indicating the beep when the stressful event occurred. The unpleasantness of this event was assessed by recoding the pleasantness scale used to indicate the occurrence of an unpleasant event (i.e. higher values indicating more unpleasant events).

\subsection{Data analysis}

All six datasets were combined into one dataset containing all variables of interest. Analyses were carried out in Stata version 13.1 (StataCorp, 2013). Group differences on time-invariant variables (age, gender, etc.) were examined using one-way ANOVAs and chisquare tests. To test the main hypotheses, multilevel analyses were carried out with individual assessments (level 1) nested within days (level 2) which in turn were nested within individuals (level 3). We first ran separate analyses per group (i.e. within-group analyses) with NA as dependent variable and time_since as predictor (coded as a factor). Based on these models, we used linear contrasts to compare the estimated average level of $N A$ at baseline (i.e., at $t_{-1}$ ) with the estimated average $N A$ at $\mathrm{t}_{0}, \mathrm{t}_{1}, \mathrm{t}_{2}$, and so on to determine if there was an initial reaction to the stressful event (i.e., $t_{0} v_{s} t_{-1}$ ) and to determine how long recovery takes within each group (i.e., where the contrast between $t_{j}$ for $j=1, \ldots, 8 \mathrm{vs}_{-1}$ is no longer significant). We then counted the number of beeps following the event where $N A$ significantly differed from time_since $=-1$ (i.e., baseline) and used this recovery period for our between-group analyses.

Next, we investigated if the patterns found in the within-group analyses were significantly different between groups. To this end, we used the entire sample of participants and added group (coded as a three-level factor) and the interaction term group*time_since as predictors to the model to investigate group differences at baseline (hypothesis I), initial reactivity (hypothesis II), and recovery (hypothesis III). Pairwise comparisons were used to further investigate potential group differences, using STATA's lincom command. To test if the time to recover differed significantly between groups, we compared the average increase (i.e., relative to $t_{-1}$ ) in $N A$ across the recovery period (i.e., all beeps $>\mathrm{t}_{0}$ where $N A$ was significantly increased compared to $t_{-1}$ ), which was determined by the abovementioned within-group analyses. For instance, for a recovery period of 2 beeps, per group we would calculate $N A$ increase as $\left(\frac{N A \mathrm{t}_{1}+N A \mathrm{t}_{2}}{2}\right)-N A \mathrm{t}_{-1}$. Finally, to account for effects of possible subsequent unpleasant events, we reran the analyses while correcting for the occurrence of further unpleasant events (i.e., after $t_{0}$ ) at the beep level (coded: $0=$ no unpleasant event; $1=$ unpleasant event). All analyses were then repeated with tense and suspiciousness as dependent variables. In all analyses, age and gender were used as covariates.

\section{Results}

\subsection{Demographics}

The 590 participants provided a total of 26,453 reports $(75 \%$ overall compliance; HV: $80 \%$; EP: $62 \%$; CP: 77\%). Of the 590 participants, 81 did not report an unpleasant event during the six days of measurement, and were therefore excluded from the analyses. The final sample thus consisted of 509 participants (HV: 220; EP: 127; CP: 162). This sample provided data on a total of 3064 days. On 1754 of those days, no stressful event was reported. Groups did not differ in number of days with versus without a stressful event $\left(\chi^{2}(2\right.$, $\mathrm{N}=3064)=3.33 ; \mathrm{p}=.189$ ). Days where no stressful event was reported were excluded from further analyses. Analyses revealed that groups differed on age, gender, total number of stressful events reported, average NA, tension, and suspiciousness. Groups did not differ on average number of days on which at least one stressful event occurred, average number of beeps available for the analyses (i.e., all beeps $\geq t_{-1}$ on days where at least one stressful event occurred), average time of day of the first stressful event of the day, or self-reported unpleasantness of the first stressful event of the day (Table 1$)$. The average since $t_{0}$ in minutes was -91.80 $\left(\right.$ S.E. $=1.05$ ) for $t_{-1}, 87.31$ (S.E. $\left.=1.06\right)$ for $t_{1}, 181.30($ S.E. $=0.97)$ for $t_{2}, 270($ S.E. $=1.18)$ for $t_{3}$, and $359.20($ S.E. $=1.21)$ for $t_{4}$, roughly resembling the average 90 -minute intervals between beeps.

\subsection{Reactivity and recovery}

\subsection{1. $N A$}

The group-wise analyses showed that EP had a different pattern of recovery compared to $\mathrm{HV}$ and $\mathrm{CP}$. In $\mathrm{HV}$, although NA was significantly increased at $\mathrm{t}_{0}$ compared to $\mathrm{t}_{-1}(\mathrm{~B}=0.160 ; \mathrm{SE}=0.031$; $\mathrm{p}<.001)$, at $\mathrm{t}_{1}$ there was no significant increase anymore $(\mathrm{B}=0.038 ; \mathrm{SE}=0.033 ; \mathrm{p}=.250)$. The same pattern was observed in $\mathrm{CP}$, with an initial increase in $\mathrm{NA}$ at $\mathrm{t}_{0}(\mathrm{~B}=0.201 ; \mathrm{SE}=0.055$; $\mathrm{p}<.001)$, but a return to baseline at $\mathrm{t}_{1}(\mathrm{~B}=0.012 ; \mathrm{SE}=0.058$; $\mathrm{p}=.841)$. In $\mathrm{EP}$, following the immediate increase $(\mathrm{B}=0.459$; $\mathrm{SE}=0.083 ; \mathrm{p}<.001)$, NA remained increased compared to baseline for $t_{1}(B=0.235 ; S E=0.089 ; p=.008), t_{2}$ (albeit at trend level significance; $B=0.175 ; S E=0.090 ; p=.052)$, and $t_{3}(B=0.206$; $\mathrm{SE}=0.093 ; \mathrm{p}=.027)$, and returned to baseline at $\mathrm{t}_{4}(\mathrm{~B}=0.038$; $\mathrm{SE}=0.096 ; \mathrm{p}=.692$ ). Therefore, as all groups' NA had returned to baseline by $t_{4}$, the recovery period was 3 beeps following $t_{0}$ and we only included $t_{1}-t_{3}$ in subsequent analyses.

Next, we repeated the analysis with the interaction term group*time_since to investigate potential group differences in 
Table 1

Basic sample characteristics.

\begin{tabular}{|c|c|c|c|c|c|c|}
\hline & $\begin{array}{l}\text { HV } \\
(220)\end{array}$ & $\begin{array}{l}\text { EP } \\
(127)\end{array}$ & $\begin{array}{l}\mathrm{CP} \\
(162)\end{array}$ & Test statistic & p-Value & Significant contrasts \\
\hline Age & 35.38 & 24.88 & 36.27 & $\mathrm{~F}(2,506)=46.20$ & $<.001$ & HV vs EP; EP vs CP \\
\hline Gender & & & & $\chi^{2}(2)=9.45$ & .009 & HV vs $\mathrm{CP}$ \\
\hline Male & $94(43 \%)$ & $68(54 \%)$ & $94(58 \%)$ & & & \\
\hline Female & $126(57 \%)$ & $59(46 \%)$ & $68(42 \%)$ & & & \\
\hline n stressful days & 3.35 & 3.62 & 3.43 & $\mathrm{~F}(2,506)=1.15$ & .317 & \\
\hline $\mathrm{n}$ beeps available & 21.64 & 19.53 & 21.38 & $\mathrm{~F}(2,506)=1.23$ & .293 & \\
\hline n stressful events & 6.05 & 8.01 & 6.74 & $\mathrm{~F}(2,506)=4.48$ & .012 & HV vs EP \\
\hline Time of first event & 1:39 PM & 1:56 PM & 1:56 PM & $\mathrm{F}(2,506)=0.56$ & .569 & \\
\hline Unpleasantness of first event & 1.80 & 1.82 & 1.94 & $\mathrm{~F}(2,506)=2.27$ & .105 & \\
\hline NA & 1.45 & 2.92 & 1.95 & $\mathrm{~F}(2,506)=107.63$ & $<.001$ & HV vs EP; HV vs CP; EP vs CP \\
\hline Tension & 3.07 & 3.99 & 3.60 & $\mathrm{~F}(2,506)=42.88$ & $<.001$ & HV vs EP; HV vs CP; EP vs CP \\
\hline Suspiciousness & 1.19 & 2.38 & 1.59 & $\mathrm{~F}(2,506)=66.21$ & $<.001$ & HV vs EP; HV vs CP; EP vs CP \\
\hline
\end{tabular}

HV: healthy volunteers; EP: early psychosis; CP: chronic psychosis; NA: negative affect.

baseline, initial reactivity, and recovery pattern during the period $t_{1}$ $-t_{3}$ (Fig. 1). There was a significant effect of group $\left(\chi^{2}(2)=153.17\right.$; $\mathrm{p}<.001)$, with higher NA in $\mathrm{EP}(\mathrm{B}=1.220 ; \mathrm{SE}=0.125 ; \mathrm{p}<.001)$ and $\mathrm{CP}(\mathrm{B}=0.557 ; \mathrm{SE}=0.110 ; \mathrm{p}<.001)$ at baseline compared to $\mathrm{HV}$, and higher baseline NA in EP compared to $\mathrm{CP}(\mathrm{B}=0.663$; $\mathrm{SE}=0.133$; $\mathrm{p}<.001$; Fig. 1). $\mathrm{EP}(\mathrm{B}=0.297 ; \mathrm{SE}=0.074 ; \mathrm{p}<.001)$, but not $\mathrm{CP}$ $(B=0.034 ; S E=0.066 ; p=.609)$, showed significantly greater initial reactivity $\left(\mathrm{t}_{0}-\mathrm{t}_{-1}\right)$ to the daily stressor than HV. Similarly, EP showed greater initial reactivity to daily stressors than $\mathrm{CP}$ $(\mathrm{B}=0.264 ; \mathrm{SE}=0.078 ; \mathrm{p}=.001)$. Significant differences were also observed regarding stress recovery, as the average NA increase (compared to baseline) during $\mathrm{t}_{1}-\mathrm{t}_{3}$ was greater in EP compared to $\mathrm{HV}(\mathrm{B}=0.185 ; \mathrm{SE}=0.068 ; \mathrm{p}=.007)$ and $\mathrm{CP}(\mathrm{B}=0.228 ; \mathrm{SE}=0.072$; $\mathrm{p}=.002)$; on the other hand, NA was not differentially increased in $\mathrm{CP}$ compared to $\mathrm{HV}(\mathrm{B}=-0.043 ; \mathrm{SE}=0.059 ; \mathrm{p}=.466)$. In addition, age was negatively related to momentary $\mathrm{NA}(\mathrm{B}=-0.010$; $\mathrm{SE}=0.004 ; \mathrm{p}=.008$ ), while gender was unrelated (female $>$ male: $\mathrm{B}=0.056 ; \mathrm{SE}=0.085 ; \mathrm{p}=.507)$.

As the differences between EP, HV and CP may have been the result of a higher frequency of stressful events in this group, we repeated the analysis controlling for occurrence of subsequent unpleasant events per beep. This variable significantly predicted momentary NA $(B=0.273 ; S E=0.032 ; p<.001)$, but the differences in recovery remained significant $([\mathrm{EP}>\mathrm{HV}: \mathrm{B}=0.155$; $\mathrm{SE}=0.068 ; \mathrm{p}=.023]$; [ $\mathrm{EP}>\mathrm{CH}: \mathrm{B}=0.209 ; \mathrm{SE}=0.072 ; \mathrm{p}=.004]$ ); while the difference between $\mathrm{CP}$ and $\mathrm{HV}$ remained non-significant $(\mathrm{B}=-0.054 ; \mathrm{SE}=0.059 ; \mathrm{p}=.359)$.

\subsubsection{Tension}

For the experience of tension, we again found no evidence for delayed recovery at $t_{1}$ in $\mathrm{HV}(\mathrm{B}=0.023 ; \mathrm{SE}=0.069 ; \mathrm{p}=.743)$ following an initial steep increase at $t_{0}$ compared to baseline $(\mathrm{B}=0.287 ; \mathrm{SE}=0.066 ; \mathrm{p}<.001)$. The same pattern was evident in $\mathrm{CP}\left(\left[\mathrm{t}_{1}>\mathrm{t}_{-1}: \mathrm{B}=0.018 ; \mathrm{SE}=0.091 ; \mathrm{p}=.842\right] ;\left[\mathrm{t}_{0}>\mathrm{t}_{-1}: \mathrm{B}=0.428\right.\right.$; $\mathrm{SE}=0.087 ; \mathrm{p}<.001])$. In $\mathrm{EP}$, after the initial increase in tension $(\mathrm{B}=0.424 ; \mathrm{SE}=0.115 ; \mathrm{p}<.001)$, there was a delay in recovery to baseline as evidenced by a significant increase from $t_{-1}$ at $t_{1}$ $(\mathrm{B}=0.255 ; \mathrm{SE}=0.123 ; \mathrm{p}=.038)$ and a just non-significant increase at $t_{2}(B=0.244 ; S E=0.125 ; p=.051)$. At $t_{3}$, tension was not significantly increased anymore $(\mathrm{B}=0.098 ; \mathrm{SE}=0.129 ; \mathrm{p}=.448)$. Consequentially, the recovery period for further tension analyses was set to two beeps following $t_{0}$.

The model including group and its interaction with time revealed a group effect for baseline tension $\left(\chi^{2}(2)=71.26\right.$; $\mathrm{p}<.001)$, where baseline tension was higher in $\mathrm{EP}(\mathrm{B}=0.783$; $\mathrm{SE}=0.148 ; \mathrm{p}<.001)$ and $\mathrm{CP}(\mathrm{B}=0.525 ; \mathrm{SE}=0.129 ; \mathrm{p}<.001)$ compared to $\mathrm{HV}$, but higher in $\mathrm{EP}$ than $\mathrm{CP}(\mathrm{B}=0.257$; $\mathrm{SE}=0.151$; $\mathrm{p}=.101)$. There were no differences in initial reactivity for feeling tense $([\mathrm{EP}>\mathrm{HV}: \quad \mathrm{B}=0.158 ; \quad \mathrm{SE}=0.123 ; \mathrm{p}=.200] ; \quad[\mathrm{CP}>\mathrm{HV}$ : $\mathrm{B}=0.152 ; \mathrm{SE}=0.110 ; \mathrm{p}=.170] ;[\mathrm{EP}>\mathrm{CP}: \mathrm{B}=0.006 ; \mathrm{SE}=0.131 ;$

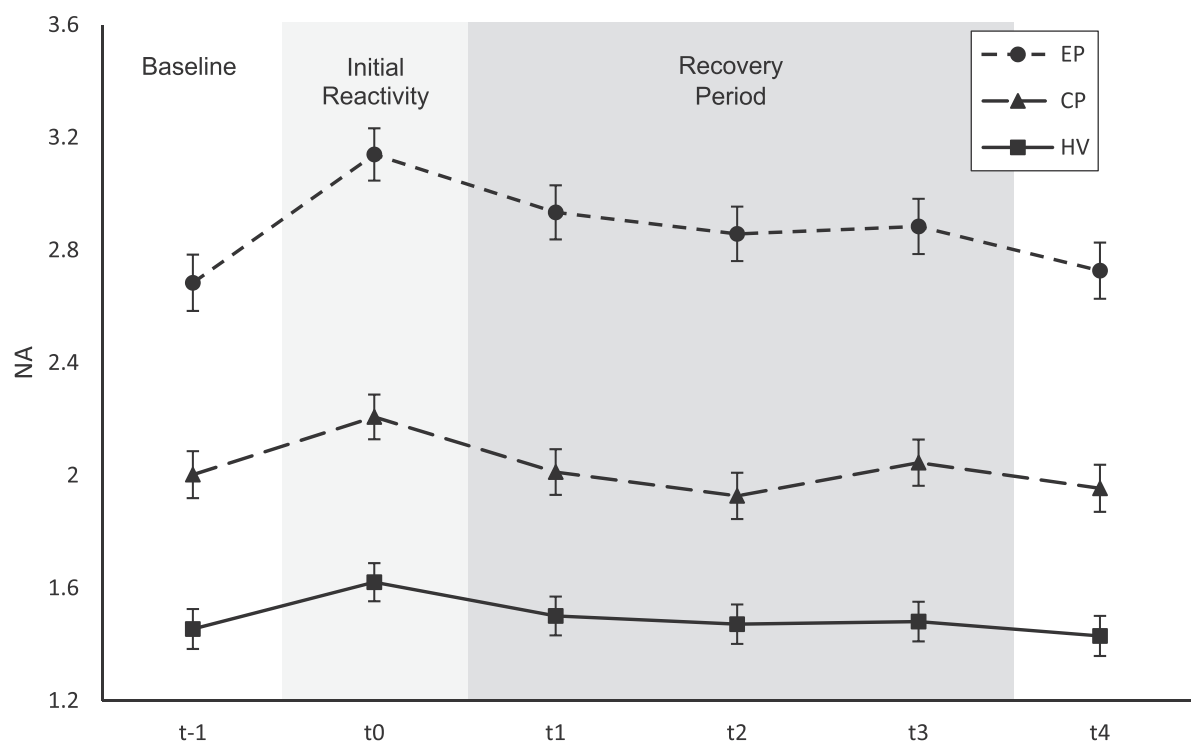

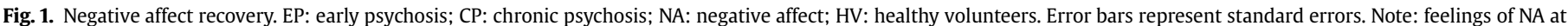
$\mathrm{t}_{4}$ were not included in the between-group analyses and are only displayed here for visual reference. 


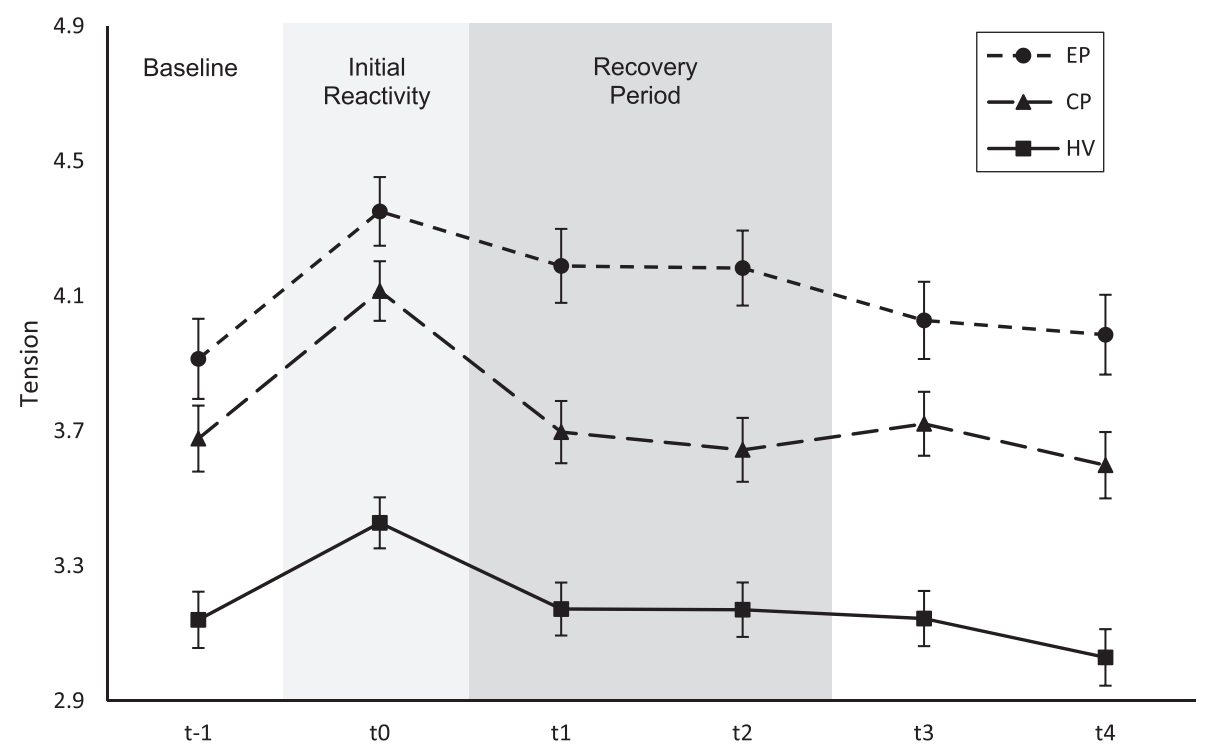

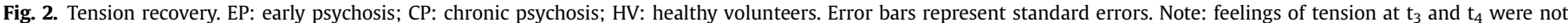
included in the between-group analyses and are only displayed here for visual reference.

$\mathrm{p}=.961$ ]; Fig. 2). During the recovery period of EP (i.e., $t_{1}$ and $t_{2}$ ), the average increase in tension from baseline was greater in EP than in $\mathrm{HV}$ and $\mathrm{CP}([\mathrm{EP}>\mathrm{HV}$ : $\mathrm{B}=0.242 ; \mathrm{SE}=0.118 ; \mathrm{p}=.040]$; $[\mathrm{EP}>\mathrm{CP}$ : $\mathrm{B}=0.284 ; \mathrm{SE}=0.125 ; \mathrm{p}=.023])$, suggesting impaired recovery in this group. There were no differences in recovery during this period between $\mathrm{CP}$ and $\mathrm{HV}(\mathrm{CP}>\mathrm{HV}: \mathrm{B}=-0.042 ; \mathrm{SE}=0.104 ; \mathrm{p}=.686)$. Age was not associated with feeling tense $(B=-0.003 ; \mathrm{SE}=0.004$; $\mathrm{p}=.494$ ), but gender was (female $>$ male: $\mathrm{B}=0.205$; $\mathrm{SE}=0.088$; $\mathrm{p}=.019)$.

Controlling for occurrence of subsequent unpleasant events again showed that this variable was a significant predictor of tension $(B=0.579 ; S E=0.062 ; p<.001)$. Furthermore, it explained part of the recovery effect for EP, as the difference between EP and HV was no longer significant $(B=0.178 ; S E=0.117 ; p=.130)$; the difference between $\mathrm{EP}$ and $\mathrm{CP}$ remained just significant $(\mathrm{B}=0.244$; $\mathrm{SE}=0.124 ; \mathrm{p}=.049)$. There was still no evidence for a difference in recovery between $\mathrm{CP}$ and $\mathrm{HV}(\mathrm{B}=-0.066 ; \mathrm{SE}=0.103 ; \mathrm{p}=.521)$.

\subsubsection{Suspiciousness}

Self-reported momentary suspiciousness increased following the stressful event in all groups $([\mathrm{HV}: \mathrm{B}=0.089 ; \mathrm{SE}=0.032$; $\mathrm{p}=.005] ; \quad[\mathrm{EP}: \mathrm{B}=0.244 ; \mathrm{SE}=0.095 ; \mathrm{p}=.011]$; $[\mathrm{CP}: \mathrm{B}=0.177$; $\mathrm{SE}=0.059 ; \mathrm{p}=.003])$. As with $\mathrm{NA}$ and tension, $\mathrm{HV}(\mathrm{B}=0.020$; $\mathrm{SE}=0.033 ; \mathrm{p}=.546)$ and $\mathrm{CP}(\mathrm{B}=-0.036 ; \mathrm{SE}=0.062 ; \mathrm{p}=.561)$ returned to their baseline level at $t_{1}$. In contrast, EP showed a delayed recovery with increased levels of suspiciousness from baseline at $\mathrm{t}_{1}(\mathrm{~B}=0.236 ; \mathrm{SE}=0.102 ; \mathrm{p}=.020)$, but not at $\mathrm{t}_{2}$ $(\mathrm{B}=0.028 ; \mathrm{SE}=0.104 ; \mathrm{p}=.785)$.

The group analysis showed that baseline levels of feeling suspicious significantly differed between groups $\left(\chi^{2}(2)=114.18\right.$; $\mathrm{p}<.001)$, such that $\mathrm{EP}(\mathrm{B}=1.184 ; \mathrm{SE}=0.136 ; \mathrm{p}<.001)$ and $\mathrm{CP}$ $(B=0.407 ; S E=0.118 ; p=.001)$ had higher baseline levels of suspiciousness than $\mathrm{HV}$, and that suspiciousness was higher in EP than in $\mathrm{CP}(\mathrm{B}=0.777 ; \mathrm{SE}=0.144 ; \mathrm{p}<.001)$. Initial reactivity was greater in $\mathrm{EP}$ compared to $\mathrm{HV}$ but the difference failed to be significant

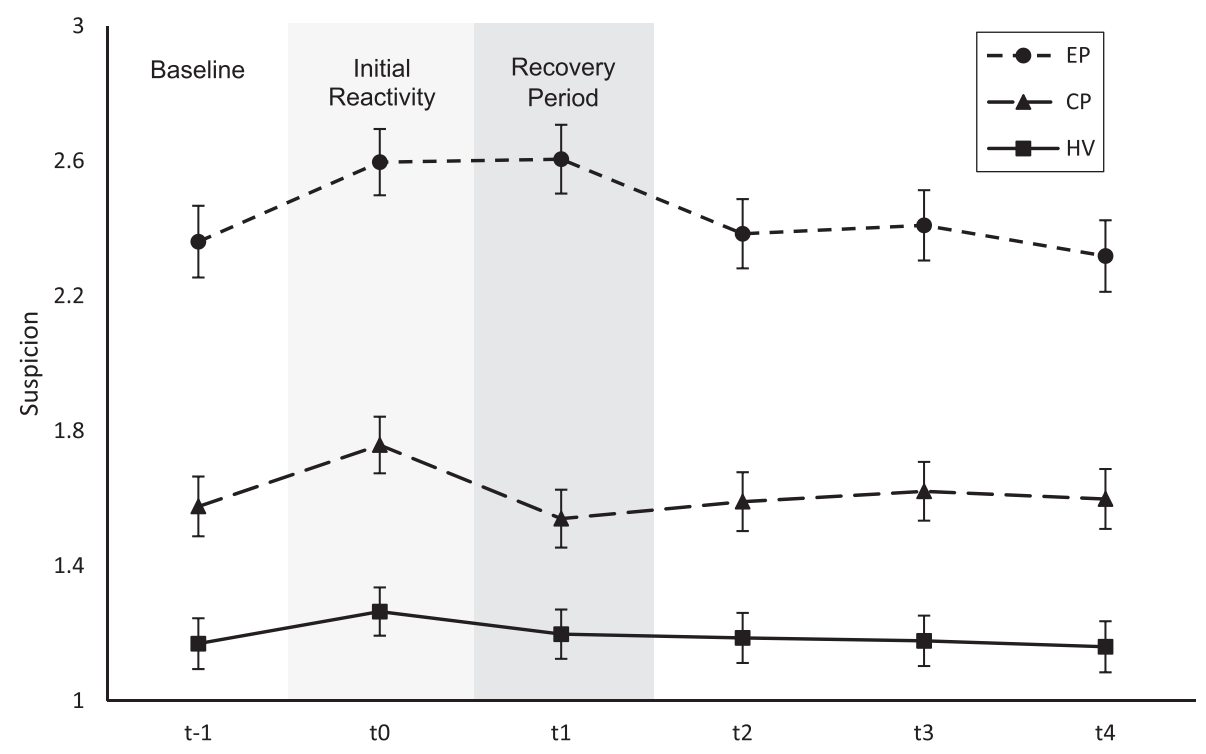

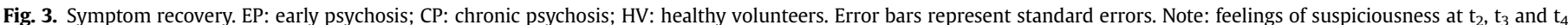
were not included in the between-group analyses and are only displayed here for visual reference. 
( $B=0.155 ; S E=0.082 ; p=.059 ;$ Fig. 3). There were no differences between $\mathrm{CP}$ and $\mathrm{HV}(\mathrm{B}=0.080 ; \mathrm{SE}=0.073 ; \mathrm{p}=.275)$ or between $\mathrm{EP}$ and $\mathrm{CP}(\mathrm{B}=0.075 \mathrm{SE}=0.087 ; \mathrm{p}=.387)$. Regarding recovery, the difference in feeling suspicious at $t_{1}$ compared to $t_{-1}$ was significantly larger in $\mathrm{EP}$ than $\mathrm{HV}(\mathrm{B}=0.223 ; \mathrm{SE}=0.087 ; \mathrm{p}=.010)$ or $\mathrm{CP}$ $(B=0.291 ; S E=0.092 ; p=.002)$, but there was no significant difference between $\mathrm{CP}$ and $\mathrm{HV}(\mathrm{B}=-0.068 ; \mathrm{SE}=0.076 ; \mathrm{p}=.376)$. Neither age $(B=-0.000 ; S E=0.004 ; p=.956)$ nor gender (female>male: $\mathrm{B}=-0.008 ; \mathrm{SE}=0.092 ; \mathrm{p}=.927$ ) was associated with suspiciousness.

Again, adding the variable coding for subsequent stressful events showed that it was a significant predictor for feeling suspicious $(\mathrm{B}=0.144 ; \mathrm{SE}=0.056 ; \mathrm{p}=.010)$. However, the group differences in recovery at $t_{1}$ remained significant after adding this variable ([EP $>\mathrm{HV}: \mathrm{B}=0.206 ; \mathrm{SE}=0.087 ; \mathrm{p}=.018] ; \quad[\mathrm{EP}>\mathrm{CP}$ : $\mathrm{B}=0.277 ; \mathrm{SE}=0.092 ; \mathrm{p}=.003]$ ), again indicating impaired recovery in EP. There was still no difference in increase in suspiciousness between $\mathrm{CP}$ and $\mathrm{HV}$ during $\mathrm{t}_{1}(\mathrm{~B}=-0.072 ; \mathrm{SE}=0.076 ; \mathrm{p}=.348)$.

\section{Discussion}

We investigated whether delayed recovery from daily stressful situations is present at various stages of psychosis. The results show that compared to both $\mathrm{HV}$ and $\mathrm{CP}$ individuals, EP individuals have a longer recovery period after stress. Concretely, EP shows a prolonged increase in NA and feelings of suspiciousness following stressful events, which we showed could not be compounded by the occurrence of subsequent stressful events. Compared to HV, but not $\mathrm{CP}$, prolonged stress-related feelings of tension were explained by a higher frequency of stressful events in EP. There were no differences in recovery between $\mathrm{HV}$ and $\mathrm{CP}$ individuals.

\subsection{Baseline and initial reactivity}

As expected, CP showed increased baseline levels of NA, tension, and suspiciousness compared to HV, suggesting that, although they may not currently experience an acute psychotic episode, $\mathrm{CP}$ is still associated with increased stress reactivity in terms of affect and symptoms. The group differences further indicated that, in the absence of stressful events, EP and CP individuals experience higher levels of NA, tension, and suspiciousness than HV individuals. Previous studies found increased overall NA during the day in EP and CP groups (Oorschot et al., 2013; Reininghaus et al., 2016; van der Steen et al., 2017), and the current study adds to these notions by showing that this increase is detectable in the absence of stressful daily events. Moreover, on all three measures, EP had higher average ratings than $\mathrm{CP}$, suggesting that the early stages of illness are particularly marked by an overall increase in distress and subclinical psychotic experiences (i.e., suspiciousness).

With regard to initial reactivity, we found no differences in NA between $\mathrm{CP}$ and $\mathrm{HV}$, which aligns with previous studies reporting no evidence for increased NA reactivity to stressful events in psychosis (Habets et al., 2012; Palmier-Claus et al., 2012; van der Steen et al., 2017). These findings parallel those found using physiological measures, where CP patients show chronic alterations in basal ANS activity, and, seemingly, unaltered immediate reactivity to stressors (Castro et al., 2008). We did, however, find a significant difference in initial NA reactivity to the first stressful events of the day between EP and HV. This is in line with previous ESM studies, which showed increased affective reactivity to daily stressors in clinical high-risk groups (Palmier-Claus et al., 2012; Reininghaus et al., 2016; van der Steen et al., 2017). At these early stages, even minor stressors may instigate psychotic vulnerability (Klippel et al., 2017), and the emergence of psychiatric symptoms is, in turn, likely to contribute to distress (van der Steen et al., 2017). Results on physiological data in a sample at a familial risk for psychosis show a different pattern (Castro et al., 2009), which could highlight a difference between clinical and familial risk states. However, although subjective arousal and the ANS are believed to be closely linked (Andrews et al., 2013), associations between them are not always consistent (Ali et al., 2017; Campbell and Ehlert, 2012) and a recent study suggests that it is the discrepancy between these systems that may differentiate individuals with psychosis or depression from healthy volunteers (Soder et al., 2018).

\subsection{Recovery}

In line with our expectations, EP showed delayed recovery of NA, tension, and suspiciousness, compared to HV. However, whereas tension was explained by the occurrence of subsequent stressful events, feelings of NA and suspiciousness persisted, regardless of subsequent stressors. Specifically, NA returned to baseline after an average increase of three subsequent beeps, following the initial rise. Given that the average time between two beeps was roughly $90 \mathrm{~min}$, this means that it took EP an average of $4 \frac{1}{2}$ hours longer to recover from stressful events than CP and HV. Regarding increased feelings of suspiciousness, the delay in recovery was on average $90 \mathrm{~min}$. These findings provide evidence for an account suggesting impaired affective recovery to stressors in EP. The results are also in line with findings on biological impairments associated with delayed recovery in psychosis, such as a diminished cortisol response and decreased responsiveness of the parasympathetic nervous system (Castro et al., 2008; Zorn et al., 2017). Whether delayed affective recovery is actually associated with these impairments in EP, however, remains to be affirmed. An alternative explanation for the delayed recovery in EP could be that the stressful events the EP individuals reported were of greater magnitude than those reported by the other groups. However, considering that groups did not differ on average self-reported unpleasantness of these events, this possibility seems less likely.

The lack of differences in recovery of feeling tense seems to suggest that it is not the prolongation of the acute fight-or-flight response that separates $\mathrm{EP}$ from $\mathrm{HV}$ and $\mathrm{CP}$. Instead, overall NA persists, which could point to impaired affective coping. Indeed, both ultra-high risk for psychosis (Mian et al., 2017) and FEP (Macdonald et al., 1998) have been associated with an emotionfocused coping style - a self-oriented strategy of handling stressors that may include reacting emotionally, selfpreoccupation, or fantasizing. Furthermore, in FEP, emotionfocused coping has been associated with higher perceived stress levels (Allott et al., 2015), implying its inefficiency. In a study in individuals with subclinical psychotic experiences, deficiencies in emotion regulation have been found to moderate the effect of daily stress on psychotic-like experiences (Krkovic et al., 2018). Maladaptive or inadequate emotional reactions to stress thus seem to aggravate psychosis. In the current study, the persistence of stressinduced NA outlasted the delayed recovery of psychotic-like experiences. However, based on these results it is not possible to infer causal relationships. More sophisticated analyses or different methodologies are needed to elucidate these interrelationships on a micro-level.

Our results revealed an unexpected lack of differences in stress recovery between $\mathrm{CP}$ and $\mathrm{HV}$. One possible explanation is that the $\mathrm{CP}$ individuals in our samples were not in an acute phase of their illness, and their stress sensitivity may have normalized or habituated to some extent. However, considering the evidence indicating impaired physiological and cortisol recovery in CP (Borges et al., 2013; Montaquila et al., 2015; Pruessner et al., 2017; Zorn et al., 2017), preserved affective recovery in this group is surprising. Additionally, there were no differences in symptomatic recovery, indicating that feelings of paranoia returned to baseline within a healthy time window in CP. The analysis method used here 
did not allow for exact determination of the timing of the full affective response to the stressor. Possibly, there was a difference in recovery within the first $90 \mathrm{~min}$ following initial reactivity. Statistical methods that allow for more fine-grained dissection of the timecourse might be more sensitive to group differences, and could shed light on the presumed delayed recovery in $\mathrm{CP}$.

Another possible explanation for the lack of differences in recovery between $\mathrm{CP}$ and HV may be that they are attributable to treatment effects. Use of antipsychotic medication has been shown to reduce allostatic load - a measure indicative of chronic stress exposure (Berger et al., 2018). As long-term antipsychotic medication use was presumably much more prevalent in the CP group than in the EP group, the group differences reported here may have been a result of pharmacotherapy, dampening initial reactivity and thus facilitating recovery. However, a recent ESM study found no difference in cortisol stress reactivity between medicated and nonmedicated psychosis patients (Vaessen et al., 2018). As the cortisol response is believed to facilitate recovery of the physiological and affective stress systems (Andrews et al., 2013), this would suggest that, at least from a neuroendocrine perspective, there is no evidence for effects of psychotropic medication on the affective recovery process. Still, a direct comparison with EP is necessary to determine the potential role of antipsychotics on stress reactivity and recovery. Similar to pharmacotherapy, CP arguably received more psychotherapy than EP, which may have trained them in coping with stressful events. As we had no information on type, duration, or effectiveness of psychotherapy in our sample, however, these effects remain subject to speculation.

\subsection{Limitations}

There are several noteworthy limitations to this study. First, the analyses revealed age and gender differences between our groups. However, gender distribution was only significantly different between the HV and CP groups, and we did not observe differences in recovery between these groups. The age effect was driven by a younger average age in the EP group compared to both other groups, which is understandable given that psychotic symptoms often first develop during adolescence or early adulthood. Age was inversely associated with NA in the recovery analyses, suggesting there was an effect over groups. However, the effect was small and unlikely to have influenced the main conclusions drawn here. Second, as we had no data on medication use over the years, we do not know what effect antipsychotic medication may have had on the current results. Similarly, we did not have data on substance use for all studies. Future research must elucidate whether the differences found between EP and CP can be subscribed to medication effects, effects of substance use, or if other factors explain these unexpected results. Third, we only considered the first stressful event of the day. Although we do not have any reason to believe recovery to subsequent events may follow a different course, taking these instances into account would have provided us with more statistical power. Future studies may investigate and compare recovery patterns following multiple stressors within a day. Fourth, due to methodological differences between studies, subclinical psychotic experiences were assessed using a single item (i.e. suspiciousness), thereby possibly limiting its reliability.

\subsection{Conclusions and future directions}

In sum, these findings confirm baseline differences and affective reactivity to stress in $\mathrm{EP}$ and $\mathrm{CP}$, whereas affective recovery was only delayed in EP. If increased negative affect at baseline reflects chronic stress, and cortisol-related dysfunction, then a greater increase may indicate a larger impairment in cortisol-driven recovery (Andrews et al., 2013), possibly explaining the differences between
EP and CP in terms of recovery. Differences in recovery between CP and HV would be expected based on this reasoning, and may have been present within a shorter timeframe than our data allow for. The current study provides evidence for a delayed affective and symptomatic recovery in EP. This resembles physiological data in psychosis showing a delayed return to baseline following stress. These findings indicate that stress may influence mental health by prolonged affective and symptomatic responses and open a window of opportunity for interventions specifically targeting coping strategies. Future studies should further investigate the temporal dynamics between initial reactivity and recovery of affect, symptoms, and physiology, and how they relate to illness progression. Recent developments in wearables technology, combined with ESM, pose an excellent candidate to study these fine-grained dynamics.

\section{Acknowledgements}

We want to thank Vera Heininga for thinking along about the analysis strategies.

\section{Conflict of interest}

All authors declare that they have no conflicts of interest.

\section{Contributors}

YvdS, TL and IMG were responsible for the study design, data collection, and data management of the iThink study. CGA, MK, LV, PM, RM, PG, TW, CM, and UR were responsible for the study design, data collection, and data management of the EUGEI study. TL, MO and IMG were responsible for the study design, data collection, and data management of the NARSAD study. JL, DC, and IMG were responsible for the study design, data collection, and data management of the STRIP1 study. DH, ZK and IMG were responsible for the study design, data collection, and data management of the STRIP2 study. PD and IMG were responsible for the study design, data collection, and data management of the MAPS study. TV and WV performed the data analyses. TV carried out the literature searches and wrote the first draft of the manuscript. WV, JL, DH, ZK, SC, UR, and IMG provided critical revisions. All authors contributed to and have approved the final manuscript.

\section{Funding}

This work was supported by an ERC consolidator grant (ERC2012-StG, project 309767 - INTERACT) to IMG and a Postdoctoral Research Fellowship of the UK National Institute for Health Research (NIHR-PDF-201104065) and a Heisenberg professorship from the German Research Foundation (389624707) to UR. TV is funded by a Research Foundation Flanders (FWO) Odysseus grant (G0F8416N) to Inez Myin-Germeys and a Horizon 2020 grant (RIA 754740).

\section{References}

Ali, N., Nitschke, J.P., Cooperman, C., Pruessner, J.C., 2017. Suppressing the endocrine and autonomic stress systems does not impact the emotional stress experience after psychosocial stress. Psychoneuroendocrinology 78, 125-130.

Allott, K.A., Rapado-Castro, M., Proffitt, T.M., Bendall, S., Garner, B., Butselaar, F. Markulev, C., Phassouliotis, C., McGorry, P.D., Wood, S.J., Cotton, S.M., Phillips, L.J., 2015. The impact of neuropsychological functioning and coping style on perceived stress in individuals with first-episode psychosis and healthy controls. Psychiatry Res. 226 (1), 128-135.

Andersen, E.H., Lewis, G.F., Belger, A., 2018. Aberrant parasympathetic reactivity to acute psychosocial stress in male patients with schizophrenia spectrum disorders. Psychiatry Res. 265, 39-47.

Andreasen, N.C., Flaum, M., Arndt, S., 1992. The Comprehensive Assessment of Symptoms and History (CASH). An instrument for assessing diagnosis and 
psychopathology. Arch. Gen. Psychiatry 49 (8), 615-623.

Andrews, J., Ali, N., Pruessner, J.C., 2013. Reflections on the interaction of psychogenic stress systems in humans: the stress coherence/compensation model. Psychoneuroendocrinology 38 (7), 947-961.

Berger, M., Juster, R.P., Westphal, S., Amminger, G.P., Bogerts, B., Schiltz, K., Bahn, S. Steiner, J., Sarnyai, Z., 2018. Allostatic load is associated with psychotic symptoms and decreases with antipsychotic treatment in patients with schizophrenia and first-episode psychosis. Psychoneuroendocrinology 90, 35-42.

Borges, S., Gayer-Anderson, C., Mondelli, V., 2013. A systematic review of the ac tivity of the hypothalamic-pituitary-adrenal axis in first episode psychosis. Psychoneuroendocrinology 38 (5), 603-611.

Brenner, K., Liu, A., Laplante, D.P., Lupien, S., Pruessner, J.C., Ciampi, A., Joober, R. King, S., 2009. Cortisol response to a psychosocial stressor in schizophrenia: blunted, delayed, or normal? Psychoneuroendocrinology 34 (6), 859-868.

Campbell, J., Ehlert, U., 2012. Acute psychosocial stress: does the emotional stress response correspond with physiological responses? Psychoneuroendocrinology 37 (8), 1111-1134.

Castro, M.N., Vigo, D.E., Weidema, H., Fahrer, R.D., Chu, E.M., de Achaval, D. Nogues, M., Leiguarda, R.C., Cardinali, D.P., Guinjoan, S.M., 2008. Heart rate variability response to mental arithmetic stress in patients with schizophrenia: autonomic response to stress in schizophrenia. Schizophr. Res. 99 (1-3), $294-303$.

Castro, M.N., Vigo, D.E., Chu, E.M., Fahrer, R.D., de Achaval, D., Costanzo, E.Y. Leiguarda, R.C., Nogues, M., Cardinali, D.P., Guinjoan, S.M., 2009. Heart rate variability response to mental arithmetic stress is abnormal in first-degree relatives of individuals with schizophrenia. Schizophr. Res. 109 (1-3), 134-140.

Clamor, A., Lincoln, T.M., Thayer, J.F., Koenig, J., 2016. Resting vagal activity in schizophrenia: meta-analysis of heart rate variability as a potential endophenotype. Br. J. Psychiatry J. Ment. Sci. 208 (1), 9-16.

Collip, D., Myin-Germeys, I., Van Os, J., 2008. Does the concept of "sensitization" provide a plausible mechanism for the putative link between the environment and schizophrenia? Schizophr. Bull. 34 (2), 220-225.

Habets, P., Collip, D., Myin-Germeys, I., Gronenschild, E., van Bronswijk, S., Hofman, P., Lataster, T., Lardinois, M., Nicolson, N.A., van Os, J., Marcelis, M. 2012. Pituitary volume, stress reactivity and genetic risk for psychotic disorder: Psychol. Med. 42 (7), 1523-1533.

Heininga, V.E., Dejonckheere, E., Houben, M., Obbels, J., Sienaert, P., Leroy, B., van Roy, J., Kuppens, P., 2019. The dynamical signature of anhedonia in major depressive disorder: positive emotion dynamics, reactivity, and recovery. BMC Psychiatry 19 (1), 59.

Hermans, K., van der Steen, Y., Kasanova, Z., van Winkel, R., Lataster, T., Wagner, M., \& Myin-Germeys, I. Temporal dynamics of suspiciousness and hallucinations in clinical high risk and first episode psychosis. Submitted.

Jansen, L.M., Gispen-de Wied, C.C., Kahn, R.S., 2000. Selective impairments in the stress response in schizophrenic patients. Psychopharmacology 149 (3), 319-325.

Klippel, A., Myin-Germeys, I., Chavez-Baldini, U., Preacher, K.J., Kempton, M., Valmaggia, L., Calem, M., So, S., Beards, S., Hubbard, K., Gayer-Anderson, C., Onyejiaka, A., Wichers, M., McGuire, P., Murray, R., Garety, P., van Os, J., Wykes, T., Morgan, C., Reininghaus, U., 2017. Modeling the interplay between psychological processes and adverse, stressful contexts and experiences in pathways to psychosis: an experience sampling study. Schizophr. Bull. 43 (2), 302-315.

Klippel, A., Viechtbauer, W., Reininghaus, U., Wigman, J., van Borkulo, C., MyinGermeys, I., Wichers, M., 2018. The cascade of stress: a network approach to explore differential dynamics in populations varying in risk for psychosis. Schizophr. Bull. 44 (2), 328-337.

Krkovic, K., Krink, S., Lincoln, T.M., 2018. Emotion regulation as a moderator of the interplay between self-reported and physiological stress and paranoia. Eur. Psychiatry J. Assoc. Eur. Psychiatrists 49, 43-49.

Lataster, T., Valmaggia, L., Lardinois, M., van Os, J., Myin-Germeys, I., 2013. Increase stress reactivity: a mechanism specifically associated with the positive symptoms of psychotic disorder. Psychol. Med. 43 (7), 1389-1400.

Lincoln, T.M., Kother, U., Hartmann, M., Kempkensteffen, J., Moritz, S., 2015. Responses to stress in patients with psychotic disorders compared to persons with varying levels of vulnerability to psychosis, persons with depression and healthy controls. J. Behav. Ther. Exp. Psychiatry 47, 92-101.

Macdonald, E.M., Pica, S., McDonald, S., Hayes, R.L., Baglioni Jr., A.J., 1998. Stress and coping in early psychosis. Role of symptoms, self-efficacy, and social support in coping with stress. The British Journal of Psychiatry. Supplement 172 (33), 122-127.

McGuffin, P., Farmer, A., Harvey, I., 1991. A polydiagnostic application of operational criteria in studies of psychotic illness. Development and reliability of the OPCRIT system. Arch. Gen. Psychiatry 48 (8), 764-770.

Mian, L., Lattanzi, G.M., Tognin, S., 2017. Coping strategies in individuals at ultra- high risk of psychosis: a systematic review (Early Interv Psychiatry).

Montaquila, J.M., Trachik, B.J., Bedwell, J.S., 2015. Heart rate variability and vagal tone in schizophrenia: a review. J. Psychiatr. Res. 69, 57-66.

Myin-Germeys, I., van Os, J., 2007. Stress-reactivity in psychosis: evidence for an affective pathway to psychosis. Clin. Psychol. Rev. 27 (4), 409-424.

Myin-Germeys, I., van Os, J., Schwartz, J.E., Stone, A.A., Delespaul, P.A., 2001 Emotional reactivity to daily life stress in psychosis. Arch. Gen. Psychiatry 58 (12), 1137-1144.

Oorschot, M., Lataster, T., Thewissen, V., Lardinois, M., Wichers, M., van Os, J., Delespaul, P., Myin-Germeys, I., 2013. Emotional experience in negative symptoms of schizophrenia-no evidence for a generalized hedonic deficit. Schizophr. Bull. 39 (1), 217-225.

Palmier-Claus, J.E., Dunn, G., Lewis, S.W., 2012. Emotional and symptomatic reactivity to stress in individuals at ultra-high risk of developing psychosis. Psychol. Med. 42 (5), 1003-1012.

Pruessner, M., Cullen, A.E. Aas, M., Walker, E.F, 2017. The neural diathesis-stress model of schizophrenia revisited: an update on recent findings considering illness stage and neurobiological and methodological complexities. Neurosci. Biobehav. Rev. 73, 191-218.

Reininghaus, U., Kempton, M.J., Valmaggia, L., Craig, T.K., Garety, P., Onyejiaka, A., Gayer-Anderson, C., So, S.H., Hubbard, K., Beards, S., Dazzan, P., Pariante, C., Mondelli, V., Fisher, H.L., Mills, J.G., Viechtbauer, W., McGuire, P., van Os, J., Murray, R.M., Wykes, T., Myin-Germeys, I., Morgan, C., 2016. Stress sensitivity, aberrant salience, and threat anticipation in early psychosis: an experience sampling study. Schizophr. Bull. 42 (3), 712-722.

Schifani, C., Tseng, H.H., Kenk, M., Tagore, A., Kiang, M., Wilson, A.A., Houle, S. Rusjan, P.M., Mizrahi, R., 2018. Cortical stress regulation is disrupted in schizophrenia but not in clinical high risk for psychosis. Brain J. Neurol. 141 (7), 2213-2224.

Schultze-Lutter, F., Addington, J., Ruhrmann, S., Klosterkötter, J., 2007. Schizophrenia Proneness Instrument, Adult Version (SPI-A). Giovanni Fioriti, Rome.

Soder, E., Clamor, A., Kempkensteffen, J., Moritz, S., Lincoln, T.M., 2018. Stress levels in psychosis: do body and mind diverge? Biol. Psychol. 138, 156-164.

StataCorp, 2013. STATA/SE Statistical Software, Release 13. College Station, TX, StataCorp.

Taylor, M.A., Abrams, R., Gaztanaga, P., 1975. Manic-depressive illness and schizophrenia: a partial validation of research diagnostic criteria utilizing neuropsychological testing. Compr. Psychiatry 16 (1), 91-96.

Vaessen, T., Kasanova, Z., Hernaus, D., Lataster, J., Collip, D., van Nierop, M., MyinGermeys, I., 2018. Overall cortisol, diurnal slope, and stress reactivity in psychosis: an experience sampling approach. Psychoneuroendocrinology 96, $61-68$.

van der Steen, Y., Gimpel-Drees, J., Lataster, T., Viechtbauer, W., Simons, C.J.P., Lardinois, M., Michel, T.M., Janssen, B., Bechdolf, A., Wagner, M., MyinGermeys, I., 2017. Clinical high risk for psychosis: the association between momentary stress, affective and psychotic symptoms. Acta Psychiatr. Scand. 136 (1), 63-73.

van Venrooij, J.A., Fluitman, S.B., Lijmer, J.G., Kavelaars, A., Heijnen, C.J., Westenberg, H.G., Kahn, R.S., Gispen-de Wied, C.C., 2012. Impaired neuroendocrine and immune response to acute stress in medication-naive patients with a first episode of psychosis. Schizophr. Bull. 38 (2), 272-279.

van Winkel, R., Stefanis, N.C., Myin-Germeys, I., 2008. Psychosocial stress and psychosis. A review of the neurobiological mechanisms and the evidence for gene-stress interaction. Schizophr. Bull. 34 (6), 1095-1105.

Walker, E., Mittal, V., Tessner, K., 2008. Stress and the hypothalamic pituitary adrenal axis in the developmental course of schizophrenia. Annu. Rev. Clin. Psychol. 4, 189-216.

Weintraub, M.J., Weisman de Mamani, A., Villano, W.J., Evans, T.C., Millman, Z.B., Hooley, J.M., Timpano, K.R., 2019. Affective and physiological reactivity to emotional comments in individuals at elevated risk for psychosis. Schizophr. Res. 206, 428-435. https://doi.org/10.1016/j.schres.2018.10.006.

Wichers, M., Peeters, F., Rutten, B.P., Jacobs, N., Derom, C., Thiery, E., Delespaul, P., van Os, J., 2012. A time-lagged momentary assessment study on daily life physical activity and affect. Health Psychol. Off. J. Div. Health Psychol. Am. Psychol. Assoc. 31 (2), 135-144.

Yung, A.R., Phillips, L.J., McGorry, P.D., McFarlane, C.A., Francey, S., Harrigan, S., Patton, G.C., Jackson, H.J., 1998. Prediction of psychosis. A step towards indicated prevention of schizophrenia. Br. J. Psychiatry Suppl. 172 (33), 14-20.

Yung, A.R., Yuen, H.P., McGorry, P.D., Phillips, L.J., Kelly, D., Dell'Olio, M., Francey, S.M., Cosgrave, E.M., Killackey, E., Stanford, C., Godfrey, K., Buckby, J., 2005. Mapping the onset of psychosis: the comprehensive assessment of at-risk mental states. Aust. N. Z. J. Psychiatry 39 (11-12), 964-971.

Zorn, J.V., Schur, R.R., Boks, M.P., Kahn, R.S., Joels, M., Vinkers, C.H., 2017. Cortisol stress reactivity across psychiatric disorders: a systematic review and metaanalysis. Psychoneuroendocrinology 77, 25-36. 